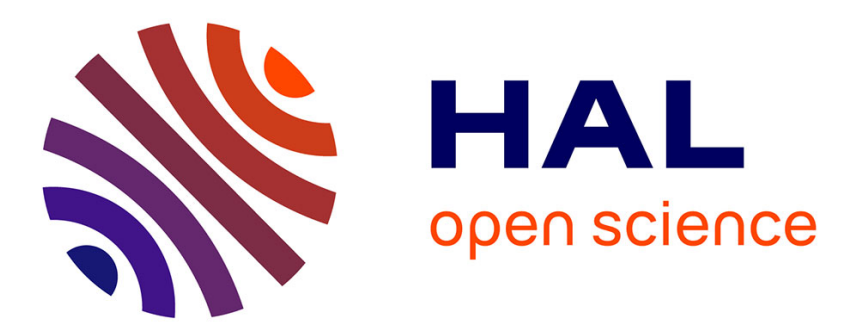

\title{
Mesospheric temperature inversions as seen by ISAMS in December 1991
}

Thierry Leblanc, Alain Hauchecorne, Marie-Lise Chanin, Clive Rodgers, Fred Taylor, Nathaniel Livesey

\section{- To cite this version:}

Thierry Leblanc, Alain Hauchecorne, Marie-Lise Chanin, Clive Rodgers, Fred Taylor, et al.. Mesospheric temperature inversions as seen by ISAMS in December 1991. Geophysical Research Letters, 1995, 22 (12), pp.1485-1488. 10.1029/94GL03274 . insu-03132098

\section{HAL Id: insu-03132098 \\ https://hal-insu.archives-ouvertes.fr/insu-03132098}

Submitted on 5 Feb 2021

HAL is a multi-disciplinary open access archive for the deposit and dissemination of scientific research documents, whether they are published or not. The documents may come from teaching and research institutions in France or abroad, or from public or private research centers.
L'archive ouverte pluridisciplinaire HAL, est destinée au dépôt et à la diffusion de documents scientifiques de niveau recherche, publiés ou non, émanant des établissements d'enseignement et de recherche français ou étrangers, des laboratoires publics ou privés. 


\title{
Mesospheric temperature inversions as seen by ISAMS in December 1991
}

\author{
Thierry Leblanc, Alain Hauchecorne and Marie-Lise Chanin \\ Service d'Aéronomie du CNRS, Verrières-le-Buisson, France
}

Clive Rodgers, Fred Taylor and Nathaniel Livesey

Clarendon Laboratory, University of Oxford, United Kingdom

\begin{abstract}
A large number of mesospheric temperature inversion layers have been observed locally in recent decades, notably by the network of French lidars. It is shown in this paper that the Improved Stratospheric and Mesospheric Sounder on board the Upper Atmosphere Research Satellite is able to detect the presence of temperature inversions, and thus allows the study of their occurrence and characteristics on a global scale. During December 1991, inversions of large amplitude (greater than $20 \mathrm{~K}$ ) are seen almost every day, especially in mid latitudes, with extent varying typically from $10^{5}$ to $10^{6} \mathrm{~km}^{2}$. Several particularly large inversions were observed at the end of the month. Their correlation with assimilated stratospheric winds is consistent with the interpretation that gravity waves propagate unfiltered through the stratosphere in the regions of strong winds, and break in the mesosphere.

The combination of high resolution lidar measurements and global satellite coverage is expected to lead to a better understanding of this significant feature of the winter mesosphere at middle latitudes.
\end{abstract}

\section{Introduction.}

Significant inversions of the vertical temperature gradient, from negative to positive, are often observed in the mesosphere around $70 \mathrm{~km}$. This feature was first measured by rocketsondes and reported by Schmidlin [1976]. Since 1981, when inversion layers were clearly observed by lidar, many such inversions have been seen between 65 and $80 \mathrm{~km}$, using lidar measurements above two sites in France. An initial statistical analysis of the occurrence of inversions was carried out by Hauchecorne et al. [1987] and showed that at least over these sites $\left(44^{\circ} \mathrm{N}, 1^{\circ} \mathrm{W}-6^{\circ} \mathrm{E}\right)$, they are very frequent (about one day on two in winter). The authors interpreted the mesospheric temperature inversions as due to gravity waves breaking in the mesosphere, and were able to reproduce their formation with a 2D model [Hauchecorne and Maillard, 1990].

To date, very little is known about the global distribution of mesospheric inversions: monthly averaged temperature profiles obtained by the Solar Mesosphere Explorer (SME) during the 1982-1986 period indicated their presence in January at $45^{\circ} \mathrm{N}$ latitude [Clancy and Rusch, 1989]. However, until recently, it was impossible to describe their global distribution, and compare it with the output of models.

\section{Copyright 1995 by the American Geophysical Union.}

Paper number 94GL03274

0094-8534/95/94GL-03274\$03.00
After the launch of the Upper Atmosphere Research Satellite (UARS) by NASA in September 1991, temperature measurements were performed by the Improved Stratospheric and Mesospheric Sounder [Taylor et al., 1993] from 30 to 80 $\mathrm{km}$ until July 1992. The comparison with simultaneous and co-located French lidar data helped to improve the retrieval algorithm and provided confidence in the validity of the profiles up to at least $70 \mathrm{~km}$ [Dudhia et al.,1993]. This triggered the search for inversion layers on a global scale between 65 and $80 \mathrm{~km}$.

The present study was performed for the Northern Hemisphere during the winter period from $0^{\circ} \mathrm{N}$ to $76^{\circ} \mathrm{N}$ for December 1991 where the occurrence of the inversions, according to lidar observations, is most frequent. First, a brief description is given of the data validation, then the method of data analysis is summarised, and finally, we present the results obtained, and their interpretation.

\section{Data validation: Comparison between the ISAMS and the OHP lidar temperature measurements.}

The satellite data used in this work is ISAMS Level 3AL temperature profiles, processing versions 5 and 7 . It consists of temperature measurements interpolated onto a grid of 4 degrees of latitude along the track of the observation point seen from the satellite. The data is presented on the standard UARS vertical grid, which is uniformly spaced in $\log$ (pressure), with 6 points in each decade:

$$
\mathrm{p}(\mathrm{k})=\mathrm{p}_{0} * 10^{-\mathrm{k} / 6}
$$

where $p_{0}$ is $1000 \mathrm{hPa}$, and the index $\mathrm{k}$ runs from 6 to typically $35(100 \mathrm{hPa}$ to $0.00147 \mathrm{hPa})$ for ISAMS temperature retrievals at level 3AL.

The characteristics of the ISAMS V0007 temperature retrieval are shown in figure 1 . This indicates that the random error on the retrieved temperatures has a minimum of about $4 \mathrm{~K}$ at $50 \mathrm{~km}$ increasing to an error of $12 \mathrm{~K}$ at about $80 \mathrm{~km}$. The widths of the averaging kernels indicate the vertical resolution of the measurements, and the integrated response indicates the fraction of the information in the retrieval which comes from the measurements. The remainder comes from climatology. The combination of the measurements and the climatology allows to minimise the final data error[ Rodgers, 1990]. Above about $80 \mathrm{~km}$, the retrieval contains a significant fraction of climatology.

Figure 2 illustrates typical comparisons between the lidar and ISAMS profiles. The lidar is located at Observatoire de Haute-Provence $\left(44^{\circ} \mathrm{N}, 6^{\circ} \mathrm{E}\right)$ and the ISAMS data is interpolated along the measurement track to $44^{\circ} \mathrm{N}$. The lidar and ISAMS 


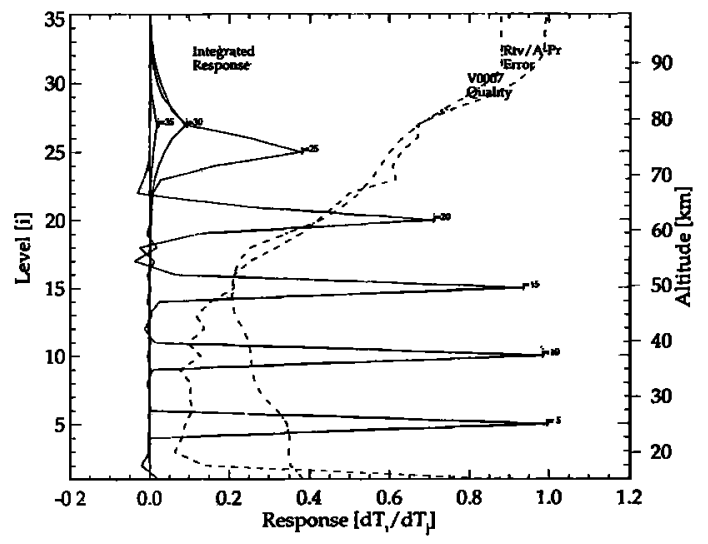

Figure 1. Characteristics of the ISAMS V0007 temperature retrieval. The solid lines are the "averaging kernels" which indicate the response of the retrieved profile to unit perturbations at the indicated levels of the "true" profile. The dotted line represents the sumaation of this response over all the levels. The dashed line indicates the ratio of the retrieved error to the climatological error $(20 \mathrm{~K})$, as produced by the error analysis, while the dashed-dot line indicates the ratio as taken from a typical day of V0007 data.

profiles were obtained on the nights of December 10/11th, $11 / 12$ th and $12 / 13$ th, 1991.

These comparisons show a general good agreement. They also indicate that the finer structure is not seen by ISAMS. However, ISAMS is able to detect inversion layers as observed by the Rayleigh lidar around 70-75 $\mathrm{km}$ (December 10th and 12th: 0.04-0.012 $\mathrm{hPa}$ ), but with smaller amplitude, due to its vertical resolution of 3-4 $\mathrm{km}$ at that height, to the horizontal smoothing of $200-400 \mathrm{~km}$ due to the limb observation and to the horizontal interpolation in the $3 \mathrm{AL}$ grid. It is thus possible to study the global extent of inversion layers of this size.

\section{Data analysis.}

The initial data was interpolated, for each day of December, onto a grid of $5^{\circ}$ of longitude for the whole Northern Hemisphere, between $0^{\circ} \mathrm{N}$ and $76^{\circ} \mathrm{N}$. The method used is similar to the 2-D Shepard's method, [Shepard, 1968] giving to each data point a weight inversely proportional to the square of the distance from the grid location. This method was chosen because of the strong spatial heterogeneity of the measurements on the track of the satellite.

Moreover, to homogenise the data field, a smoothing over five points $\left(25^{\circ}\right.$ of longitude, corresponding approximately to the distance between two northward tracks or two southward tracks) was carried out. This somewhat reduces the effects of the atmospheric tides [Dudhia et al., 1993], as between the southward and northward tracks the local solar time differs at low latitudes by more than 9 hours. Though this smoothing does not completely remove the tidal effects on the temperature field, particularly in the mesosphere, it can be considered as adequate for the study of inversion layers whose amplitude should not be much affected by tides.

The interpolated data now comprises one 3-D temperature field per day from December 5th to $31 \mathrm{st}, 1991$, on a grid of $73 \times 20 \times 24$ points from $0^{\circ}$ to $360^{\circ}$ longitude, $0^{\circ}$ to $76^{\circ}$ latitude, and level $12(10 \mathrm{hPa}$, about $32 \mathrm{~km})$ to level $35(0.00147 \mathrm{hPa}$, about $94 \mathrm{~km}$ ), in altitude.

An algorithm was developed to identify the presence of an inversion in the vertical temperature gradient between the stratopause and level $30(0.01 \mathrm{hPa})$. Higher levels are not used, as the inclusion of a significant fraction of climatology in the retrieved profile can sometimes generate spurious inversions. At each 2-D latitude-longitude grid point, the temperature difference $T_{\max }-T_{\min }$ between the top and the base of the strongest inversion layer of each profile was calculated. Considering the various sources of uncertainties on the temperature, only inversions with amplitude greater than $12 \mathrm{~K}$ are considered significant.

\section{Results and discussion}

An examination of the inversion layers seen by ISAMS in the Northern Hemisphere each day of December 1991 shows that:

1. Inversion layers are present almost every day somewhere in the hemisphere.

2. Inversion regions seem to exist mostly in a mid-latitude belt.

3. The amplitude of the inversions often reaches more than 20 K.

4. The horizontal extent of the regions of inversion is variable, from $10^{5}$ to $10^{6} \mathrm{~km}^{2}$.

The polar maps of figure 3 show the existence, the position and amplitude of the inversions during 5 selected days in December. Few inversions are observed the 13th, but many

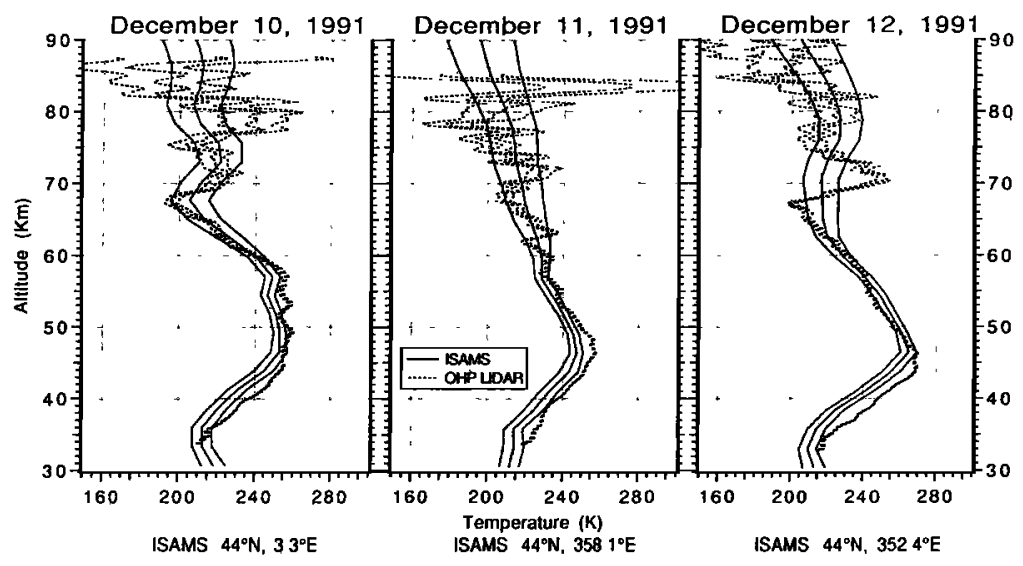

Figure 2. Comparison between ISAMS profiles and lidar profiles (Observatoire de Haute Provence, $44^{\circ} \mathrm{N}, 6^{\circ} \mathrm{E}$ ) 


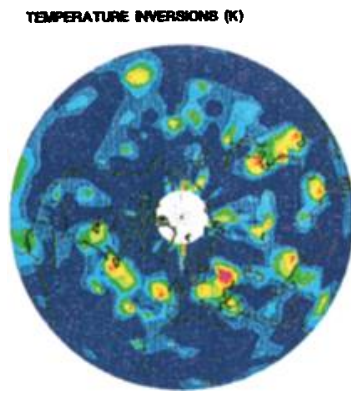

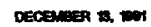

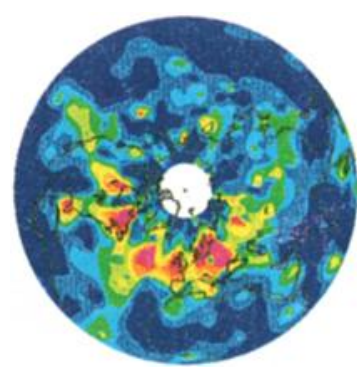

DEceseren 2 nor
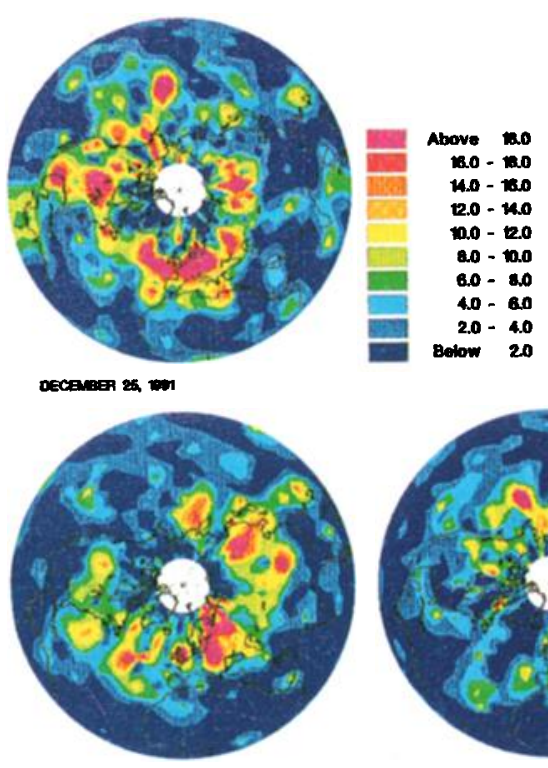

Deceater 20, war

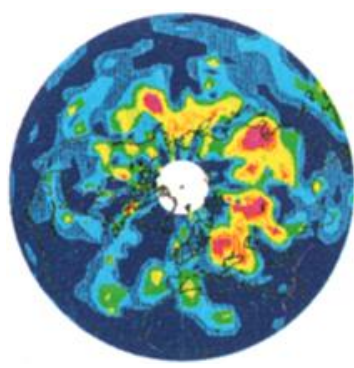

Decarater 30 wor
Figure 3. Daily mean amplitude of mesospheric temperature inversions seen by ISAMS for five days of December 1991 (K). occur during the other days presented. These maps show the strong day to day variability of the temperature inversions. This variability could be due either to the data analysis (existence of a "criteria" which can generate a "threshold effect" in the research of the inversions), or to physical processes (strong variability of the gravity waves forcing for example).

Looking at the last three days of December, we can observe the generation and then the eastward motion of large inversions. This motion is likely to be due to the eastward advection of the inversions by the mesospheric mean flow, as we will see later.

The observed scales of the inversions seem to be consistent with the possible role of gravity waves and their breaking in the mesosphere. This led us to investigate the meteorological situation in the troposphere and stratosphere, where the mean flow can play a very important role for filtering gravity waves.

We used the UKMO assimilated winds for the same period, for the first 22 UARS pressure levels (from the ground to $0.316 \mathrm{hPa}$ ). The two maps shown in figure 4 give the monthly mean amplitude of mesospheric inversions and the monthly mean strength of the zonal wind at $1 \mathrm{hPa}$. The similarity observed between them seems to confirm the relationship to the propagation and breaking of gravity waves. A strong westerly jet at this altitude is favourable to the propagation of gravity waves, because there will be no critical level, and favourable to the efficiency of their breaking just above, because friction on a zonal mean flow proportional is to $|\mathrm{U}-\mathrm{cl}|^{3}$ [Lindzen et al., 1981], with lck $10 \mathrm{~ms}^{-1}$ for most orographic waves.

However, this similarity is not systematic on a day-to-day basis, notably for the smallest inversions. This may be due to the complex role of sources, filtering and breaking of gravity waves, which cannot be resolved by examination of a simple assimilated zonal wind field. Moreover, the smallest scales involved in the theory of gravity wave propagation are not resolved in this global study.

While good correlation is observed between the inversions and the $1 \mathrm{hPa}$ wind on the 29th, the data shows less correlation on the 30th and 31st, in particular the set of inversions above China. This can be explained by the eastward advection of the inversions generated three days before above Central Asia and not yet eroded by radiative transfer (damping rate of less than 0.3 day $^{-1}$ for perturbations with vertical wavelength of about $20 \mathrm{~km}$ at $75 \mathrm{~km}$ altitude) [Andrews et al., 1987]. The inversion layers of smaller amplitude may have shorter life-time due to either shorter damping rates or to the variability of gravity waves activity.

Finally, inversion layers can be observed South of the jet. We recently developed a $2-\mathrm{D}$ mesoscale $\left(20^{\circ} \mathrm{N}-70^{\circ} \mathrm{N}\right)$ mechanistic model to try to produce inversion layers in midlatitudes. In this model, a localised drag (about $48^{\circ} \mathrm{N}, 70 \mathrm{~km}$ altitude) generates a local 2-D circulation cell, with adiabatic

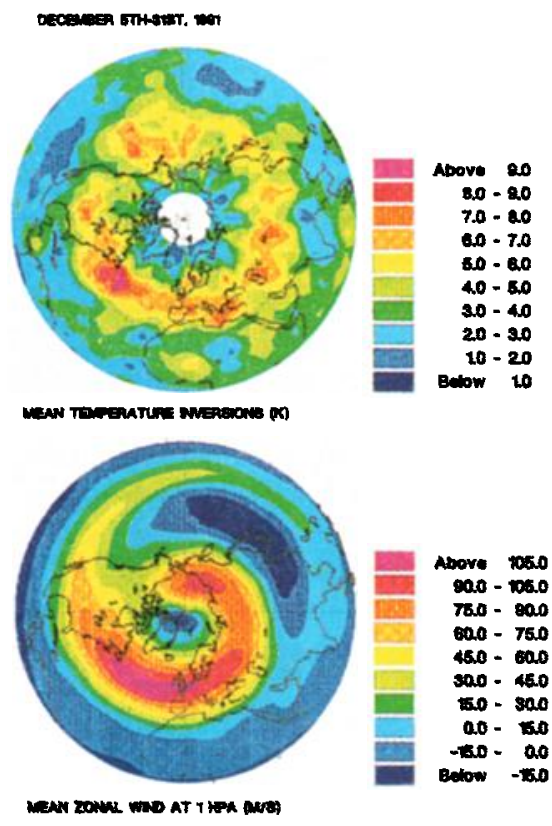

Figure 4. Monthly Mean (December 5th-31st) amplitude of mesospheric temperature inversions seen by ISAMS ans assimilated zonal winds at $1 \mathrm{hPa}$ (from UKMO). 


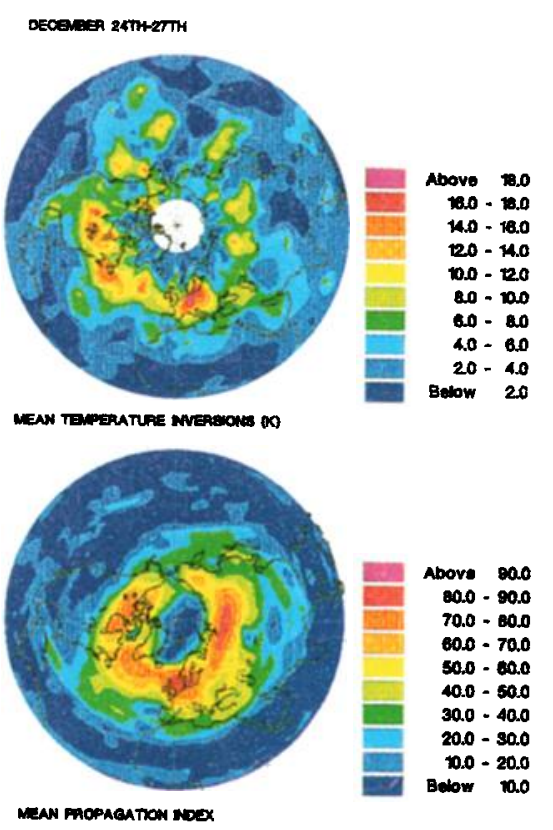

Figure 5. Mean amplitude of temperature inversions seen by ISAMS and propagation index of gravity waves calculated from UKMO winds (December 24th-27th).

heating (respectively cooling) in the southern descending (respectively ascending) branch of the cell. This combined heating and cooling leads to the generation of an inversion layer South of the jet which could explain the occurrence of temperature inversions in mid-latitudes.

These first results, while not explaining the mechanism of generation of mesospheric temperature inversions, show nevertheless that gravity waves may play a role in their characteristics. More investigations, particularly concerning the sources and the upward propagation of gravity waves are necessary. To this end we calculated several very simplified normalised indexes of vertical transmission of orographic waves, to take account of the filtering in the low winds layers, generally at the surface and about $50 \mathrm{hPa}$. One of these indexes is given, for each day and each point of the longitude-latitude grid, by:

$$
\mathrm{I}=\frac{\mathrm{U}_{\min }}{\mathrm{U}_{\min }^{*}} \cdot \frac{\mathrm{U}_{1}}{\mathrm{U}_{1}^{*}} \cdot 100
$$

where $U_{\min }$ is the minimum intensity of the wind in the profile, $\mathrm{U}_{1}$ the intensity of the wind at $1 \mathrm{hPa}$, and the asterisk represents the maximum of these intensities in the hemisphere during the given day. Thus, for low minimum winds and low winds at $1 \mathrm{hPa}$, the index is near to 0 (total filtering), but for high minimum winds and strong jets at $1 \mathrm{hPa}$, the index is near to 100 (total transmission and efficiency). Figure 5 shows a good correlation between the amplitude of inversions and the index of transmission during the period of 24th-27th of December. It shows that both the strong jet of the lower mesosphere and weak winds in the lower stratosphere may generate a favourable pattern for the propagation of the gravity waves with a minimum of dissipation, but shows that a more sophisticated index is necessary to take into account of all the processes involving gravity waves.

Moreover, the planetary waves, their breaking or their interaction with gravity waves may play an important role in the generation of inversion layers. This question has to be developed in the future.

\section{Conclusion.}

It is shown in this paper that temperature data provided by ISAMS aboard UARS are able to provide a global distribution of inversion layers with a quite high degree of confidence. The temperature inversions seem to occur frequently, with variable amplitude and extent. The limited number of data which have been treated so far does not allow the complete explanation of the observed phenomena, but indicates nevertheless that the occurrence of such inversions relates to the circulation pattern in the stratosphere, confirming a possible role of gravity wave filtering. More cases need to be studied using both ground based lidar data and data from ISAMS or other instruments on board UARS to confirm this relationship and to find a possible way of predicting the presence of inversions in the mesosphere.

\section{References:}

Andrews, D.G., J.R. Holton, C.B. Leovy, Middle Atmosphere Dynamics, pp70-72, Academic Press, Inc., Orlando, 1987.

Clancy, R.T. and D.W. Rusch, Climatology and trends of mesospheric (58-90 km) temperatures based upon 1982-1986 SME limb scattering profiles, J. Geophys. Res.,94, 3377-3393, 1989.

Dudhia, A., N.J. Livesey and F.W.Taylor, Validation of ISAMS retrievals of atmospheric temperature and pressure, Adv. in Space Res., 14, (9)237-(9)241, 1993.

Dudhia A., S.E. Smith, A.R. Woodand F.W Taylor, Diurnal and semidiurnal temperature variability of the middle atmosphere, as observed by ISAMS, Geophys. Res. Letters, 20, 1251-1254, 1993.

Hauchecorne, A., M.L. Chanin, R. Wilson, Mesospheric temperature inversion and gravity wave breaking, Geophys. Res. Letters, 14, 933936, 1987

Hauchecorne, A., A. Maillard, A 2-D dynamical model of mesospheric temperature inversions in winter, Geophys. Res. Letters, 17, 2197 2200,1990

Lindzen, R.S.., Turbulence and stress owing to gravity wave and tidal breakdown, J. Geophys.Res., 86, 9707-9714, 1981.

Rodgers, C.D., Characterization and Error Analysis of profiles Retrieved From Remote Sounding Measurements, J. Geophys.Res., 95, 5587, 1990.

Schmidlin, F.J., Temperature inversions near 75 km, Geophys.Res. Letters, 3, 173-176, 1976.

Shepard, D., A two dimensional interpolation function for irregulary spaced data, Proc. 23rd Nat. Conf. ACM, Brandon/Systems Press Inc., Princeton, 517-523, 1968.

Taylor, F.W., C.D. Rodgers, J.G.Whitney, S.T. Werrett, J.J. Barnett, G.D. Peskett, P. Venters, J. Ballard,C.W.P. Palmer, R.J. Knight, P.J. Morris and T.J. Nightingale, Remote sensing of atmospheric structure and composition by pressure modulator radiometry from space: the ISAMS experiment on UARS,J. Geophys. Res., 98, 10799-10814, 1993.

M. L. Chanin, Service d'Aéronomie du CNRS, BP3, 91371 Verrièresle-Buisson Cedex, France. (e-mail: chanin @aerov.jussieu.fr)

A. Hauchecorne, Service d'Aéronomie du CNRS, BP3, 91371

Verrières-le-Buisson Cedex, France. (e-mail: hauche@aerov.jussieu.fr)

Thierry Leblanc, Service d'Aéronomie du CNRS, BP3, 91371

Verrières-le-Buisson Cedex, France. (e-mail: leblanc@aerov.jussieu.fr)

N., J. Livesey, Atmospheric Oceanic and Planetary Physics, Oxford University, Parks Road, Oxford OX1 3PU, U.K.

C. D. Rodgers, Atmospheric Oceanic and Planetary Physics, Oxford University, Parks Road, Oxford OX1 3PU, U.K.

F. W. Taylor, Atmospheric Oceanic and Planetary Physics, Oxford University, Parks Road, Oxford OX1 3PU, U.K.

(Received: August 12, 1994; revised October 17, 1994; Accepted November 15, 1994.) 